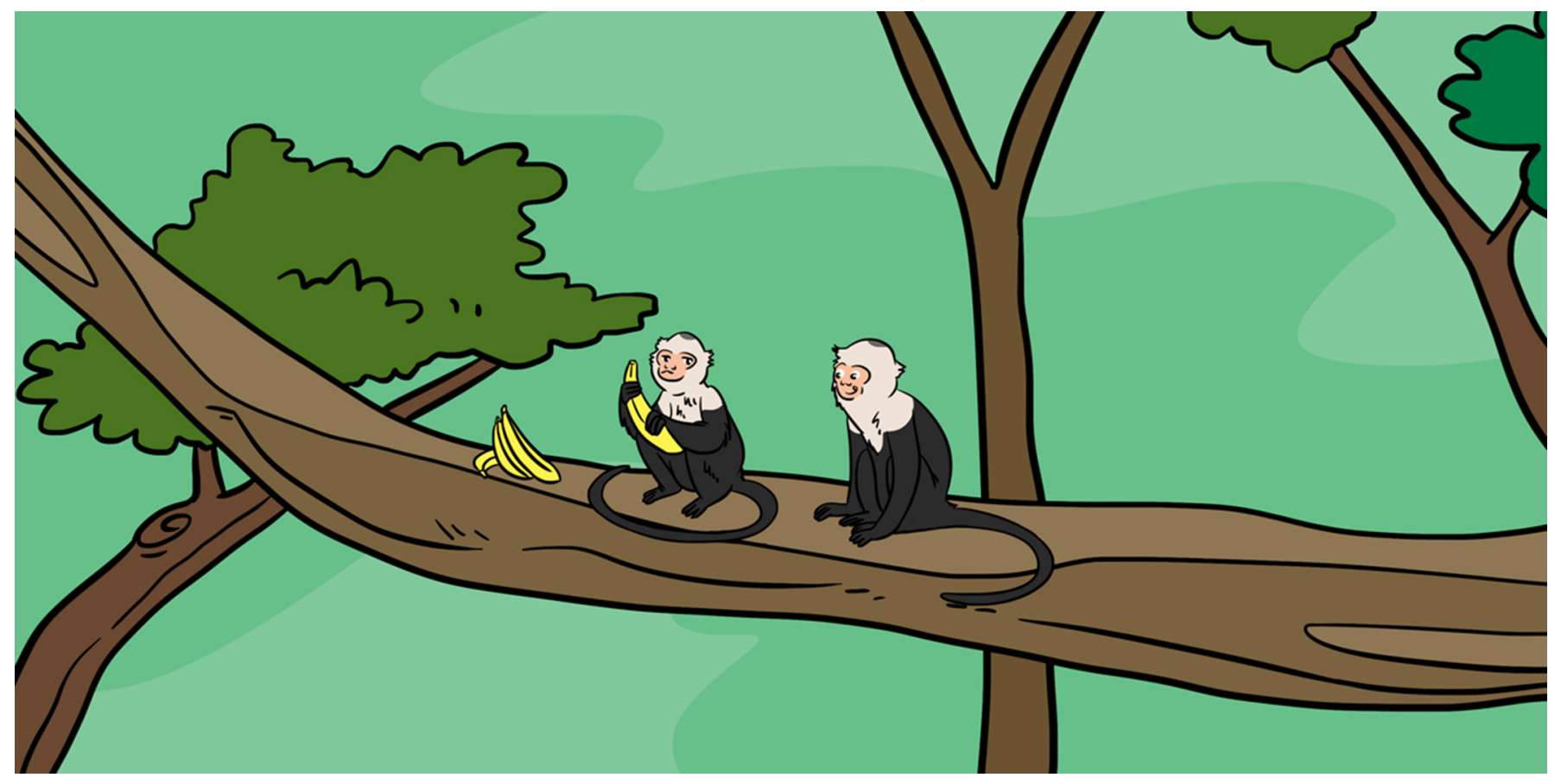

\title{
DO MONKEYS CARE WHAT IS FAIR?
}

\section{Katherine A. Cronin ${ }^{1^{*}}$ and Lydia M. Hopper ${ }^{2}$}

${ }^{1}$ Animal Welfare Science Program, Lincoln Park Zoo, Chicago, IL, United States

${ }^{2}$ Lester E. Fisher Center for the Study and Conservation of Apes, Lincoln Park Zoo, Chicago, IL, United States

\section{YOUNG REVIEWERS:}

EVOLEIPZIG

COMMUNITY SCIENCE LAB

AGES: $12-13$
Scientists study fairness in humans, apes, and monkeys to understand the evolutionary origins of our own behavior and to better understand the behavior of other primates. Scientists studying monkeys have found that, sometimes, monkeys will share food equally with others, but their choices often depend on their species and the specific circumstances. Monkeys are more likely to help friends, but even then, monkeys rarely go out of their way to act fairly. Furthermore, while monkeys appear to recognize unfair outcomes, they only seem concerned by inequity when they receive less than others, not when they receive more.

\section{WHY DO WE WANT TO KNOW IF MONKEYS HAVE A SENSE OF FAIRNESS?}

Imagine that you are celebrating your friend's birthday. Together with a group of friends, you have worked together to bake and frost a delicious birthday cake. Your friend has just blown out the candles and is slicing the cake to share with all the guests. The first three guests are 
Figure 1

Test for whether monkeys prefer that others receive rewards, too. (Left) The monkey can choose either tray, both of which have food on them. When the monkey pulls one tray to get the food, the other tray is no longer accessible. (Center) The monkey on the left has just chosen the tray gives food to both himself and the neighboring monkey, resulting in equitable rewards. (Right) Here, the monkey on the left has just chosen the tray that provides food for himself only, resulting in inequitable rewards.

\section{INEQUITY}

AVERSION

When an individual responds negatively to receiving a different reward than they deserve, typically shown by rejecting the reward they are offered or by refusing to participate in the activity further.

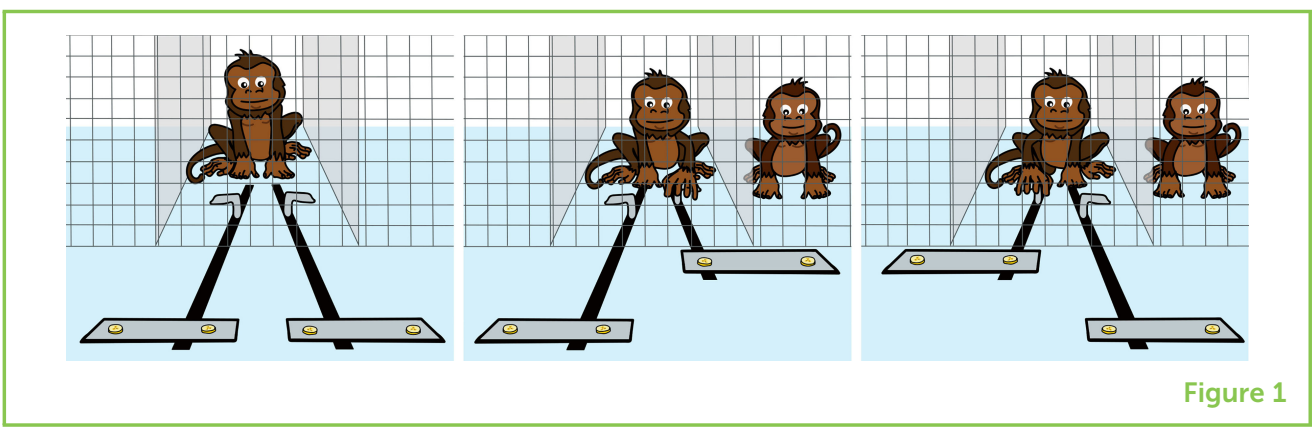

handed large slices of cake, and then it is your turn. You are handed a teeny-tiny, skinny slice of birthday cake. How would you feel? Is this fair? Most of us have a clear sense of what is fair and what is not, but where does this come from? Fairness is the idea that people are treated equally, and rewarded fairly for the effort they have put in.

Scientists tend to study fairness in humans, apes, and monkeys to understand the evolutionary origins of this behavior. By studying a range of primate species, scientists can start to understand how fairness came about. In this article, we discuss whether monkeys have a sense of fairness. Scientists also study fairness in species even more distant from humans, such as domestic dogs and elephants [1], to better understand how fairness emerges in the animal kingdom.

\section{SHARING YOUR CANDY: FAIRNESS OFTEN INVOLVES EQUAL OUTCOMES}

Suppose you and your friend find four pieces of candy on the kitchen table. You might pick up the candy and share one piece with your friend. That would be very kind of you! However, you would still have three pieces of candy while your friend would only have one. This decision does not lead to equal outcomes. To be fair, you would need to give two pieces of candy to your friend so that you each have two pieces. Your friend would likely be happier in this case, because s/he would have the same number of pieces of candy as you. People typically do not like getting less than someone else; this is called inequity aversion.

Do monkeys behave in ways that lead to equal outcomes? To find out, scientists give monkeys choices about how to divvy up rewards, generally small pieces of food that they really like. Scientists will ask a monkey to choose between two options-one that provides a piece of food just to themselves, and another option that provides an equal reward to another monkey nearby, as well as to themselves (Figure 1). If monkeys are seeking to create equal outcomes, they would choose the option that provides a piece of food to both themselves and another. Do they? Sometimes. 


\section{COOPERATIVE}

\section{BREEDING}

When members of the social group other than the biological parents help raise the offspring in the group.

\section{SPECIES AND FRIENDSHIPS INFLUENCE FAIRNESS}

Whether monkeys favor equal outcomes seems to depend on the species (there are more than 200 species of monkeys, and so far, scientists have studied fairness in about a dozen species). One idea that scientists have considered to explain species differences is the called the cooperative breeding hypothesis. This hypothesis predicts that species, such as marmosets and tamarins, which live in family groups and help raise babies that are not their own, will be more tuned in to fairness [2]. In some cases, monkeys that are cooperative breeders choose the equal outcome in the experiment, but not all the time. Also, sometimes species that are not cooperative breeders, such as capuchin monkeys, make the equal choice, so there seems to be a bit more going on.

What else might be influencing whether monkeys seek equal outcomes? It seems like monkeys are more likely to make the equal choice when they have a good friendship with the other monkey who will benefit. It also seems that monkeys are more likely to make the equal choice when they cannot see the food they are divvying up. Monkeys, like other animals, get very excited by the sight of food they like, and have a harder time making decisions when food is in front of them. For that reason, some scientists have used touchscreen computers that show images instead of actual food items, or have asked monkeys to make choices using symbolic representations of food, such as tokens.

All in all, a lot of different things seem to influence whether a monkey makes the equal choice. However, even in the cases where monkeys do make equal choices, they seem to do less frequently or consistently than humans do. Even scientists who have shown that monkeys prefer the equal choice find that the monkeys do not make that choice as often as they could if fairness was very important to them. This might mean that monkeys are capable of recognizing fairness, and creating fairness, but they do not think it is important all of the time.

\section{BUT WAIT, DOES EFFORT MATTER?}

Let us return to the candy scenario. We considered the situation to be equitable, or fair, if you and your friend each had two pieces of the candy. We focused on the results being equal. But what if you earned that candy by doing chores around the house? Is the fairest outcome still for you and your friend, who did not do any chores, to end up with two pieces of candy each? Probably not, because people tend to consider the effort involved when considering what is fair. What if you and your friend both complete chores, but only you get candy? That also would not seem fair. Scientists have also considered how monkeys' choices are impacted by how much each monkey had to work for the rewards. 
Figure 2

Test for whether monkeys dislike inequity. The monkey on the left has taken a red token from a scientist, and now exchanges the token for a piece of banana. Next, the neighbor monkey will also exchange a token, but receive a less-preferred piece of food. Scientists test how monkeys feel about inequity by measuring whether they stop exchanging tokens, or stop taking the food they are offered.

\section{INEQUITY}

An unfair outcome in which one individual receives a different reward than they deserve, such as unequal pay for equal work.

\section{ADVANTAGEOUS INEQUITY}

An unfair outcome in which one individual receives more than other individual for doing the same amount of work (opposite: disadvantageous inequity).

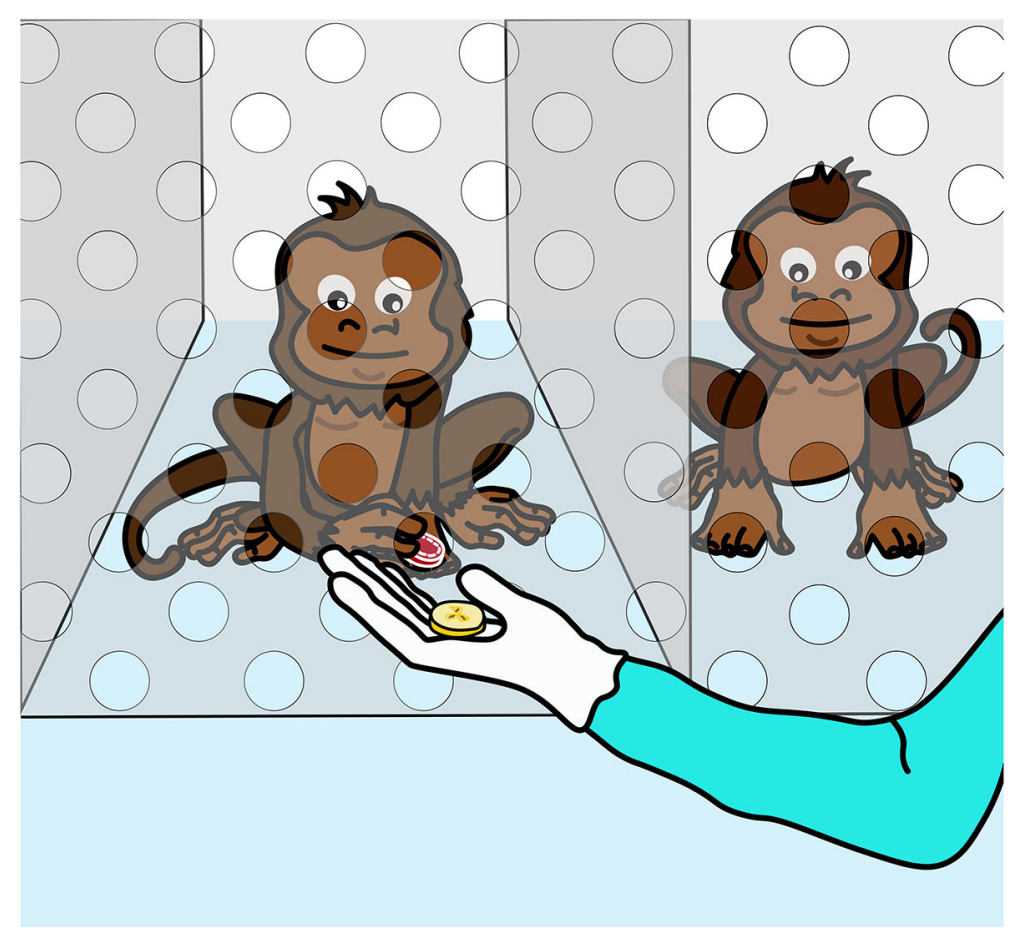

Figure 2

Scientists have developed a way to test whether monkeys prefer everyone to be paid equally for doing the same amount of work. In these studies, monkeys are trained to work for rewards by exchanging small plastic tokens with a scientist (Figure 2). Every time the monkey exchanges a token, it gets a small piece of food. To determine if, and how, monkeys respond to inequity, scientists have two monkeys take turns exchanging tokens. Each time, the scientist gives one monkey a food that monkeys really like (like a slice of banana) but gives the second monkey a less-preferred food (like a piece of cucumber). So, while both monkeys are working equally hard by exchanging tokens, they are rewarded differently.

If the monkey getting the less-preferred food refuses to keep exchanging tokens or to eat the food it is given, scientists conclude the monkeys are averse to inequity-they are aware they are getting less than the other monkey, which is not fair, and they quit. In contrast, if the monkey getting the better food refuses to exchange or take rewards, scientists conclude that the monkeys are sensitive to advantageous inequity (for example, getting more than the other monkey for the same work, which is also unfair).

Scientists have run these kinds of inequity aversion tests with a few different monkey species, including rhesus macaques, capuchin monkeys, squirrel monkeys, night monkeys (also called owl monkeys), and marmosets [3]. Like the sharing studies described earlier, these studies have revealed that there are differences across monkey species. Generally, monkeys that are cooperative breeders (such as 
marmosets) do not respond to inequity. In contrast, other monkeys (such as capuchins) do respond to inequity: when they are getting a less-preferred food than another monkey for the same work, they refuse to keep working and/or reject the food they are offered. Monkeys do not appear to respond to advantageous inequity, however. That is, they do not tend to mind if they get a better reward than others [4].

\section{WHAT ABOUT WILD MONKEYS?}

The research we have discussed has taken place in zoos and laboratories. But do we see evidence of fairness in monkey behavior in the wild? We certainly see monkeys acting in ways that help each other out. For example, vervet monkeys give alarm calls to warn their group about nearby predators, cottontop tamarins chirp and alert others to the presence of good food, and baboons form coalitions to support each other in fights. Yet, in other contexts, we see monkeys acting selfishly and sometimes even deceiving one another to ensure they get the most for themselves [5]. Whether the monkeys understand the amount of benefits they each gain and the amount of work they each contribute is not clear from these observations. That is why the experiments discussed above can help scientists understand to what degree fairness plays a role in the behaviors we observe.

\section{CONCLUSIONS}

Ultimately, monkeys' sense of fairness does not seem to be as well-developed as our own, but by studying monkeys' preferences for fairness, and their responses to unfair situations, we can learn more about how these values evolved in humans. People are inherently interested in knowing why we are the way we are, and if we are unique from other animals. When we learn about other primates, and how their minds work, we learn more about ourselves. We also learn more about the monkeys-whether they pay attention to what others get, what they find unfair, how these responses depend on relationships, and how monkey species differ from one another. This helps us to understand the natural world, and can sometimes help us better understand how to care for them in captivity as well.

\section{REFERENCES}

1. Cronin, K. A., and Hopper, L. M. 2017. "A comparative perspective on helping and fairness," in Social Cognition: Development Across the Life Span. Frontiers of Developmental Science Series, eds J. Sommerville and J. Decety (New York, NY: Routledge; Taylor and Francis Group). p. 26-45. 
2. Burkart, J. M., Hrdy, S. B., and van Schaik, C. P. 2009. Cooperative breeding and human cognitive evolution. Evol. Anthropol. 18:175-86. doi: 10.1002/evan. 20222

3. Brosnan, S. F. 2013. Justice- and fairness-related behaviors in nonhuman primates. Proc. Natl. Acad. Sci. U.S.A. 110:10416-23. doi: 10.1073/pnas. 1301194110

4. Freeman, H. D., Sullivan, J., Hopper, L. M., Talbot, C. F., Holmes, A. N., Schultz-Darken, N., et al. 2013. Different responses to reward comparisons by three primate species. PLOS ONE 8:e76297. doi: 10.1371/journal.pone.0076297

5. Hall, K., and Brosnan, S. F. 2017. Cooperation and deception in primates. Infant Behav. Dev. 48:38-44. doi: 10.1016/j.infbeh.2016.11.007

SUBMITTED: 09 April 2020; ACCEPTED: 26 October 2020;

PUBLISHED ONLINE: 04 December 2020.

EDITED BY: Guilherme Lucas, University of São Paulo, Brazil

CITATION: Cronin KA and Hopper LM (2020) Do Monkeys Care What Is Fair? Front. Young Minds 8:550299. doi: 10.3389/frym.2020.550299

CONFLICT OF INTEREST: The authors declare that the research was conducted in the absence of any commercial or financial relationships that could be construed as a potential conflict of interest.

COPYRIGHT () 2020 Cronin and Hopper. This is an open-access article distributed under the terms of the Creative Commons Attribution License (CC BY). The use, distribution or reproduction in other forums is permitted, provided the original author(s) and the copyright owner(s) are credited and that the original publication in this journal is cited, in accordance with accepted academic practice. No use, distribution or reproduction is permitted which does not comply with these terms.

\section{YOUNG REVIEWERS}

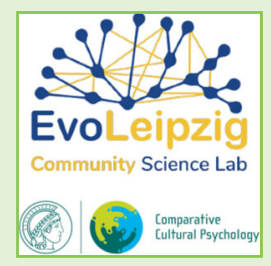

\section{EVOLEIPZIG COMMUNITY SCIENCE LAB, AGES: 12-13}

The EvoLeipzig Community Science Lab is a project of the Department of Comparative Cultural Psychology at the Max Planck Institute for Evolutionary Anthropology. We are scientists, students, and teachers working to understand big questions regarding what it means to be human, and how humans can cooperate around global sustainability. This youth review was conducted by students from the local seventh grade class, Sophie, Hannah, Magdalena, Samantha, Luise, Emily, Amelie, Leni, Fabiana, Niels, Eddie, Paul, and Jessica.

\section{AUTHORS}

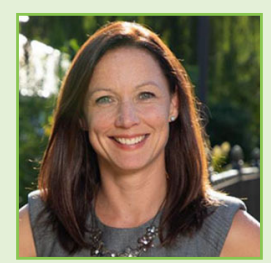

\section{KATHERINE A. CRONIN}

I am the Senior Animal Welfare Scientist at Lincoln Park Zoo, leading the Animal Welfare Science Program, and am faculty on the Committee on Evolutionary Biology at the University of Chicago. My research focuses on animal behavior and cognition, 
and I apply this work to create environments in which animals thrive in human care. *kcronin@lpzoo.org

\section{LYDIA M. HOPPER}

I am interested in how primates solve problems and learn new skills from copying others. I apply what I discover about primate cognition to improve how we care for these animals in a captive setting. I am the Assistant Director of the Lester E. Fisher Center for the Study and Conservation of Apes at Lincoln Park Zoo. I direct the zoo's primate research program, in which we use touchscreen computers to better understand primate cognition and well-being. 